\title{
SUGARCANE BAGASSE LIGNIN OBTAINED BY DIFFERENT EXTRACTION METHODS
}

\author{
JANAÍNA ALVES CARVALHO, ${ }^{*}$ MAYARA DE SOUZA MIRANDA, \\ MATHEUS FELIPE FREIRE PEGO, ${ }^{* *}$ ELTON FRANCISQUINI, ${ }^{*}$ DIEIMES RIBEIRO RESENDE ${ }^{* *}$ \\ and MARIA LUCIA BIANCHI* \\ *Department of Chemistry (DQI), Universidade Federal de Lavras, Zipcode 37200-900, 3037, Lavras, MG, \\ Brazil \\ "** Department of Forest Sciences (DCF), Universidade Federal de Lavras, Zipcode 37200-900, 3037, \\ Lavras, MG, Brazil \\ \Corresponding author: M. de Souza Miranda,mayara_s_m@hotmail.com
}

Received June 30, 2020

Sugarcane bagasse (SB) is a by-product of ethanol production obtained in large quantities worldwide, including Brazil. Lignin is one of SB components, and its extraction is of great interest due to its vast potential for use. In this study, sugarcane bagasse was subjected to two methods of lignin extraction to obtain: Klason lignin (LKL) and milled wood lignin (MWL). The syringil/guaiacyl ratio of the lignin obtained from sugarcane bagasse was 1.67. Thermogravimetric analysis showed that LKL is more resistant to thermal degradation than MWL. According to the FTIR spectra, LKL yields a more oxidized lignin, presenting greater changes in its structure than MWL. Thus, this study provides information on the changes caused by different extractions and strengthens future studies on the transformation of lignin into products of high added value.

Keywords: Klason, milled wood lignin, biomass

\section{INTRODUCTION}

Brazil is the largest producer of sugarcane in the world and the first to produce sugar and ethanol from this raw material. The high production generates sugarcane bagasse (SB) as by-product, which presents great potential for use. $^{1-3}$ The most common uses of SB include fuel and fertilizers. Nevertheless, there are still no viable technologies for obtaining materials and inputs of greater economic value from SB. Lignin is one of the components of SB that can be potentially used in many value added applications. $^{4}$

Lignin is a polymeric material consisting of different cross-linked bonds of p-hydroxyphenyl $(\mathrm{H})$, guaiacyl $(\mathrm{G})$ and syringyl $(\mathrm{S}){ }^{5,6}$ There is a wide range of methods of lignin extraction from lignocellulosic materials. However, due to the complexity of its structure, no method can isolate lignin in its native form without causing changes in the original structure. Therefore, since each method produces a different and modified lignin, its subsequent conversion and application is challenging. ${ }^{7.8}$

Thus, studies focusing on the characterization of sugarcane bagasse lignin can elucidate changes caused in the chemical structure and assist in the discovery of new methods and technologies for converting this biomass. ${ }^{9}$ Tian and collaborators ${ }^{10}$ used aqueous $62 \%$ formic acid at $130{ }^{\circ} \mathrm{C}$ to extract lignin from wheat straw. The results showed that lignin presented an uncondensed structure, with $81 \%$ of ether bond retention and molar mass of $3016 \mathrm{~g} \mathrm{~mol}^{-1}$. The authors emphasized the advantage of the method due to the fact that lignin did not undergo many modifications. Chaudhary and Dhepe ${ }^{11}$ extracted lignin from coconut fiber using the methods of Klason, Organosolv and the alkaline method. The results showed that the yield of lignin extracted by the Klason method was 4 to 6 times greater than those of the other studied methods. Klason lignin presented the highest molar mass and the highest maximum decomposition temperature

Cellulose Chem. Technol., 55 (1-2), 55-62(2021) 
$\left(390{ }^{\circ} \mathrm{C}\right)$ when compared with alkaline lignin $\left(375^{\circ} \mathrm{C}\right)$ and Organosolv lignin $\left(335^{\circ} \mathrm{C}\right)$.

Bortoluz and collaborators ${ }^{12}$ extracted lignin from Pinus elliottii sawdust by the Klason method. The physical-chemical characterizations showed that lignin was essentially constituted by oxygenated functional groups composed of particles of different shapes and sizes, in addition to presenting high thermal stability, with a mass loss of $35.5 \%$ at $415^{\circ} \mathrm{C}$ and $20.1 \%$ at $613^{\circ} \mathrm{C} .{ }^{12}$

Lignin extraction methods used for wood can be applied with adaptations to grasses, such as sugarcane bagasse. ${ }^{13,14}$ The Klason method removes polysaccharides from the material by the acid hydrolysis reaction, with lignin obtained as by-product. ${ }^{15}$ In the solvent extraction process of milled wood lignin (MWL), organic solvents (toluene, dioxane and acetone, among others) are used during the grinding of the lignocellulosic material in a ball mill, causing only minor changes in the material structure. ${ }^{16}$

The knowledge regarding the structure of lignin from sugarcane bagasse extracted by different methods is very important, since it can be used as a tool to explore the potential of this by-product, considering the obtention of chemical inputs and biocomposites. Thus, this study evaluated the characteristics of Klason lignin and milled wood lignin extracted from sugarcane bagasse.

\section{EXPERIMENTAL \\ Material}

The raw material used in this study was sugarcane bagasse (SB) (Saccharum spp.) donated by Cachaça Bocaina, located at Rodovia BR 265, km 349, Lavras, state of Minas Gerais. The material was processed in a knife mill, sieved at $5.5 \mathrm{~mm}$ and dried at $60{ }^{\circ} \mathrm{C}$.

\section{Characterization of sugarcane bagasse}

The quantification of the elemental components: carbon, hydrogen, nitrogen and sulfur, was carried out in triplicate in a universal elementary analyzer, model Vario Micro Cube. The mass of each dry sample used was approximately $2 \mathrm{mg}$, which was packed in a tin capsule and incinerated at $1200{ }^{\circ} \mathrm{C}$. The quantification of oxygen was performed by difference.

Instrumental analyses of sugarcane bagasse were performed in triplicate. The determination of the superior calorific power (PCS) was carried out according to the ASTM E711-87 ${ }^{17}$ in a digital calorimeter model IKA C-200, using a $0.3 \mathrm{~g}$ sample with granulometry of $40-60$ mesh, dried at $103 \pm 2{ }^{\circ} \mathrm{C}$ in a muffle furnace until constant weight. The useful and inferior calorific values (PCU and PCI) were calculated according to Faria and collaborators. ${ }^{18}$
The humidity of the sugarcane bagasse on dry base (Ubs) and wet base (Ubu) was determined according to the norm DIN EN $14774-1^{19}$ using a muffle furnace at $105 \pm 2{ }^{\circ} \mathrm{C}$.

The apparent density (DA) was determined under ambient conditions of temperature and relative humidity. A test tube of $1000 \mathrm{~cm}^{3}$ was filled with sugarcane bagasse and weighed on a scale with precision of $0.1 \mathrm{~g}$. The DA value was obtained by dividing the mass obtained from weighing by the sample volume $\left(1000 \mathrm{~cm}^{3}\right)$.

The upper energy density (DES), lower energy density (DEI) and the useful energy density (DEU) were obtained by multiplying the apparent density by the upper, lower and useful calorific value, respectively.

The extracts were determined in an ethanol/toluene solution of $1: 2(\mathrm{v} / \mathrm{v})$, according to the standard method NBR 14853. ${ }^{20}$ Total lignin (soluble and insoluble Klason method) was determined according to Gomide and Demuner. $^{15}$

The immediate chemical characterization to quantify the composition of volatile materials, ashes and fixed carbon was carried out according to the standard method ASTM D1762-84. ${ }^{21}$

The quantitative analysis of syringyl and guaiacyl monomers was carried out by oxidation with nitrobenzene according to the procedures described by Lin and Dence, ${ }^{22}$ with adaptations. Chromatography was performed on a Shimatzu CBM-20A device, equipped with a UV-SPD-20A detector, operating at a wavelength of $280 \mathrm{~nm}$, using an LC-18 column, the oven temperature of $40{ }^{\circ} \mathrm{C}$ and the injection sample volume of $10 \mu \mathrm{L}$. The mobile phase used was acetonitrile/water $(1: 6 \mathrm{v} / \mathrm{v})$, with a flow rate of $1.0 \mathrm{~mL}$ $\min ^{-1}$, adjusting the $\mathrm{pH}$ to 2.6 with $5 \%$ trifluoroacetic acid. Standard vanillin solutions were used to obtain the calibration curves in the following concentrations: $0.10,0.15,0.21,0.30,0.50,0.75$ and $1.50 \mathrm{mmol} \mathrm{L}^{-1}$ for derivatives of guaiac units and standard syringaldehyde solutions in the concentrations of 0.22 , $0.33,0.47,0.66,1.10,1.65$ and $3.30 \mathrm{mmol} \mathrm{L}^{-1}$ for derivatives of syringyl units. The solutions were prepared in an acetonitrile/water mixture $(1: 1 \mathrm{v} / \mathrm{v})$.

\section{Extraction of lignin from sugarcane bagasse Klason method (LKL)}

Lignin was obtained using the Klason method according to the methodology proposed by Gomide and Demuner ${ }^{15}$ using SB free of extracts. The extractives were obtained using an ethanol:toluene solution of 1:2(v/v), according to the standard method TAPPI T $204 \mathrm{~cm}-97 .^{23} 3 \mathrm{~mL}$ of $72 \%$ sulfuric acid and $0.3 \mathrm{~g}$ of SB were placed in a test tube and left in an water bath at $30{ }^{\circ} \mathrm{C}$ for $1 \mathrm{~h}$. Soon after, it was transferred to $100-\mathrm{mL}$ flasks and sealed. The bottles were heated to $120{ }^{\circ} \mathrm{C}$ for a period of $60 \mathrm{~min}$. The contents were vacuum filtered in capped crucibles. The 
samples were dried at $50{ }^{\circ} \mathrm{C}$ for $24 \mathrm{~h}$ and stored in a desiccator.

\section{Milled wood lignin (MWL)}

Lignin was obtained according to the methodology proposed by Bjorkman, ${ }^{24}$ and Balakshin and collaborators, ${ }^{13}$ with adaptations, starting with the raw sample. The determination of the extractive contents of SB was carried out according to the standard method ABTCP - M5/68. ${ }^{25}$ Extraction was performed during 6 $\mathrm{h}$ after mixing $600 \mathrm{~mL}$ of $1 \%(\mathrm{~m} / \mathrm{v}) \mathrm{NaOH}$ and $35.0 \mathrm{~g}$ of SB without agitation. The extract was vacuum filtered and washed with a water/acetone mixture (1:1 $\mathrm{v} / \mathrm{v})$, followed by drying for $24 \mathrm{~h}$ at $60{ }^{\circ} \mathrm{C}$.

To obtain MWL, approximately $25 \mathrm{~g}$ of free extractives SB sample was placed in a Marconi ball mill with $750 \mathrm{~mL}$ of toluene (P.A.) for a period of 12 $\mathrm{h}$. The ground mixture was centrifuged at $8000 \mathrm{rpm}$ for $25 \mathrm{~min}$ and the supernatant was discarded. The solid material was treated with $500 \mathrm{~mL}$ of dioxane/water in the ratio of $96: 4(\mathrm{v} / \mathrm{v})$, which was kept under agitation for five days. The sample was centrifuged at $8000 \mathrm{rpm}$ for $25 \mathrm{~min}$ and the supernatant was discarded. To the solid material, $90 \%$ acetic acid was added and left to stand for $2 \mathrm{~h}$. The sample was centrifuged at $8000 \mathrm{rpm}$ for $25 \mathrm{~min}$ and the supernatant was discarded. Subsequently, $200 \mathrm{~mL}$ of chloroform was added to the solid content and it was left to stand for 7 days. Then, the material was again centrifuged and $50 \mathrm{~mL}$ of $75 \%$ ethanol was added. The mixture was left under stirring for $2 \mathrm{~h}$ for subsequent centrifugation, and $75 \mathrm{~mL}$ of dichloroethane and ethanol (ratio of 2:1) was added and the sample was left to stand for $2 \mathrm{~h}$. The material was oven dried at $60{ }^{\circ} \mathrm{C}$ for $12 \mathrm{~h}$.

\section{Characterization of extracted lignin samples}

Thermogravimetric analyses of the extracted lignin samples were performed at a heating rate of $10^{\circ} \mathrm{C} \mathrm{min}$

${ }^{1}$ with temperature ranging from 25 to $900{ }^{\circ} \mathrm{C}$ under synthetic air atmosphere $\left(50 \mathrm{~mL} \mathrm{m^{-1 }}\right)$, using a DTG60H-SHIMADZU Thermomechanical Analyzer. The initial sample weight used was approximately 10 mg.

Differential exploratory calorimetry analyses were performed in the temperature range from $25^{\circ} \mathrm{C}$ to 570 ${ }^{\circ} \mathrm{C}$, with the heating rate of $10{ }^{\circ} \mathrm{C} \min ^{-1}$ under nitrogen atmosphere and flow of $30 \mathrm{~mL} \mathrm{~min}^{-1}$, using DSC-60Ab Differential Scanning Calorimeter Shimadzu equipment. The initial sample weight used was approximately $8 \mathrm{mg}$.

The lignin samples were analyzed by spectroscopy in the infrared region with Fourier transform (FTIR) in $\mathrm{KBr}$ tablets, using IRAffinity-1 equipment from Shimadzu, with 32 scans, and the resolution of $4 \mathrm{~cm}^{-1}$ in the range of 4000 to $400 \mathrm{~cm}^{-1}$.

Elementary analysis of carbon, hydrogen, nitrogen and sulfur was carried out in triplicate, using a Universal Elementary Analyzer Model Vario Micro Cube. The mass of each dry sample was approximately
$2 \mathrm{mg}$. The sample was packed in a tin capsule and incinerated at $1200{ }^{\circ} \mathrm{C}$.

The determination of the superior calorific power was carried out according to the norm NBR 8633, ${ }^{26}$ using an IKA C-200 Digital Calorimeter. Samples of $1.5 \mathrm{~g}$ were weighed for analysis, in triplicates, placed in a crucible and heated in the oven for $2 \mathrm{~h}$ at $103{ }^{\circ} \mathrm{C}$. Subsequently, the crucible was placed in a desiccator.

\section{RESULTS AND DISCUSSION Characterization of sugarcane bagasse}

The physical-chemical characteristics of sugarcane bagasse are directly related to its application as a raw material. The chemical composition has an impact on the use of sugarcane bagasse for pulping and production of cellulose, as well as the energy characterization, which is important when bagasse is used as an energy source. $^{27,28}$

Sugarcane bagasse was characterized regarding its contents of macromolecular, extractive and ash components, among others (Table 1).

Lignin is the chemical constituent that most contributes to the increase in calorific value ${ }^{29}$ of biomass, because it contains a higher amount of carbon, when compared with cellulose and hemicelluloses (holocelluloses). Holocelluloses present a variety of oxygen atoms, which constitute a larger portion of the cell wall (up to $59 \%)$.

According to Ripoli and collaborators, ${ }^{30}$ the values of superior calorific power (PCS) of SB are similar, regardless of the region in which sugarcane is cultivated and the varieties of species, differing more in relation to their ash content and humidity. There is a decrease in PCS as humidity increases, while the maximum energy release value is reached when humidity is close to zero. ${ }^{31}$ The same occurs in the case of the ash content, as the calorific value of the biomass decreases with the increase of the ash content. ${ }^{32}$

Table 1 shows the results of ash content $(0.58 \%)$ and moisture on dry base $(8.97 \%)$ and wet base $(8.22 \%)$. Similar values were found in the literature for the humidity of SB. Katyal and collaborators $^{33}$ obtained a value of $8.2 \%$ for bagasse moisture, whereas Pereira and $\mathrm{Seye}^{34}$ found a value of $10.08 \%$. These results provide better energy efficiency to the material. There are several studies in the literature that associate the PCS of biomass with immediate and elementary chemical analysis. According to Protásio and collaborators, ${ }^{32}$ and Huang and collaborators, ${ }^{35}$ 
the carbon and hydrogen contents are positively related to the higher calorific value of biomass. The oxygen content contributes to the combustion of the sample, but it does not increase its calorific value.

According to Quirino, ${ }^{36}$ the values of PCS for wood and different lignocellulosic materials are in the range of $14.00 \mathrm{MJ} \mathrm{kg}^{-1}$ and $22.00 \mathrm{MJ} \mathrm{kg}^{-1}$. In the literature, PCS for SB was $15.48 \mathrm{MJ} \mathrm{kg}^{-1}$, while the maximum value was reported for pine coastal wood (up to $21.07 \mathrm{MJ} \mathrm{kg}^{-1}$ ). ${ }^{36}$ According to Nhuchhen and Salam, ${ }^{37}$ the PCS values of different biomasses can vary from 5.63 to 23.46 $\mathrm{MJ} \mathrm{kg}^{-1}$.

Yin $^{38}$ and Nhuchhen and Salam ${ }^{37}$ found PCS values of $\mathrm{SB}$ between $17.32 \mathrm{MJ} \mathrm{kg}^{-1}$ and 18.73 MJ kg-1. Silva and Morais, ${ }^{39}$ who carried out energy analysis of SB, found a PCS value of 18.24 $\mathrm{MJ} \mathrm{kg}^{-1}$. Aló and collaborators ${ }^{40}$ found PCS results of $15.96 \mathrm{MJ} \mathrm{Kg}^{-1}$ and $14.61 \mathrm{MJ} \mathrm{kg}^{-1}$ for the lower calorific value (PCI). Fernandez and collaborators, ${ }^{41}$ in their study on SB, found a PCS value of $16.47 \mathrm{MJ} \mathrm{kg}^{-1}$.

Thus, the values obtained in relation to the upper, lower and useful calorific value (Table 1) in the present study are consistent with the values reported in the literature. The differences in the values of the calorific value of the sugarcane bagasse found in different studies can be related to several factors, such as granulometry, humidity and density of the bagasse, among others.

An S/G ratio of 1.67 was found in the quantification of syringyl and guaiacyl monomers. The greater number of syringil units indicates that the sugarcane bagasse lignin has a low degree of condensation. ${ }^{42}$ The advantage is that the higher the $\mathrm{S} / \mathrm{G}$ ratio, the easier it is to remove lignin from lignocellulosic material. ${ }^{43}$ The delignification process depends not only on the accessibility of lignin, but also on its reactivity, which is influenced by the $\mathrm{S} / \mathrm{G}$ ratio. ${ }^{44}$ According to Chiang, ${ }^{43}$ more units of syringil or high $\mathrm{S} / \mathrm{G}$ ratios provide greater reactivity of lignin. Río and collaborators $^{42}$ also demonstrated that lignin from SB (Sccharum spp hybrid) predominantly presents syringyl groups. Furthermore, this study showed that this lignin is basically formed by alkyl-aryl-ether substructures ( $\beta-\mathrm{O}-4$ 'bonds).

Table 1

Results of chemical and immediate analyses of sugarcane bagasse

\begin{tabular}{lc}
\hline Attribute & Value \\
\hline Holocellulose & $59.26 \%$ \\
Insoluble lignin (LI) & $18.92 \%$ \\
Soluble lignin (LS) & $2.34 \%$ \\
Total lignin & $21.26(\mathrm{LI}+\mathrm{LS}) \%$ \\
Extractives & $18.90 \%$ \\
Volatile & $85.27 \%$ \\
Fixed carbon & $14.14 \%$ \\
Ashes & $0.58 \%$ \\
$\mathrm{C}$ & $47.38 \%$ \\
$\mathrm{H}$ & $6.20 \%$ \\
$\mathrm{~N}$ & $1.36 \%$ \\
$\mathrm{~S}$ & $0.03 \%$ \\
O* & $44.45 \%$ \\
Higher calorific value (PCS) & $18.79 \mathrm{MJ} \mathrm{kg}^{-1}$ \\
Lower calorific value (PCI) & $17.38 \mathrm{MJ} \mathrm{kg}^{-1}$ \\
Useful calorific value (PCU) & $15.75 \mathrm{MJ} \mathrm{kg}^{-1}$ \\
Dry base humidity (UBs) & $8.97 \%$ \\
Humid base moisture (UBu) & $8.22 \%$ \\
Apparent density (DA) & $63.3 \mathrm{~kg} \mathrm{~m}^{-3}$ \\
Higher energy density (DES) & $1.19 \mathrm{GJ} \mathrm{m}^{-3}$ \\
Lower energy density (DEI) & $1.10 \mathrm{GJ} \mathrm{m}^{-3}$ \\
Useful energy density (DEU) & $1.00 \mathrm{GJ} \mathrm{m}^{-3}$ \\
Syringil & $2.53 \mathrm{mg} \mathrm{L}^{-1}$ \\
Guaiacyl & $1.51 \mathrm{mg} \mathrm{L}^{-1}$ \\
S/G & 1.67 \\
\hline obtained by difference &
\end{tabular}




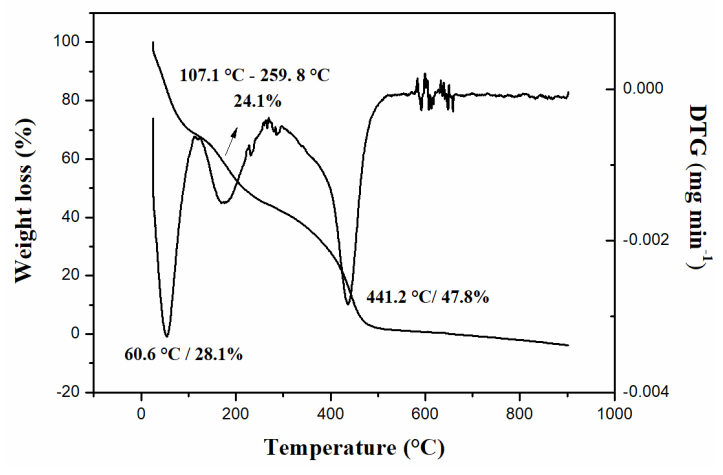

Figure 1: TG of Klason lignin (LKL)

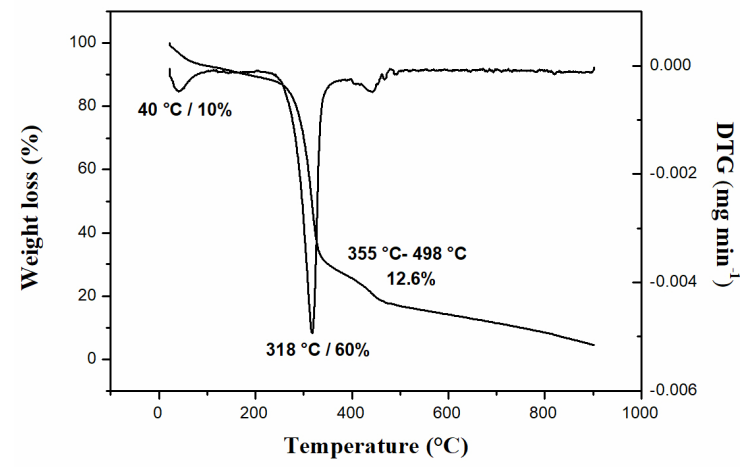

Figure 2: TG of milled wood lignin (MWL)

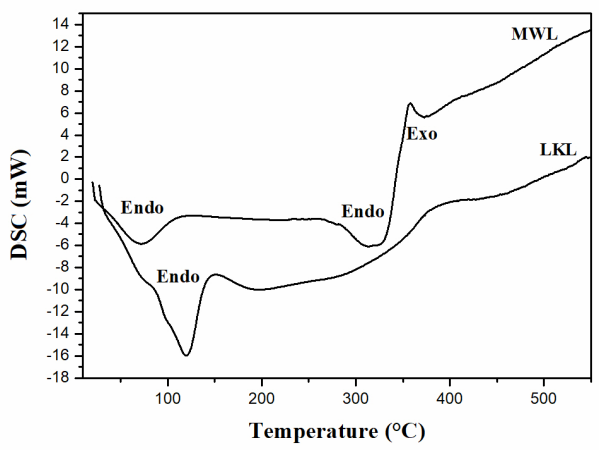

Figure 3: DSC of milled wood lignin (MWL) and Klason lignin (LKL)

\section{Characterization of extracted lignin samples}

The thermal stability of the lignin samples was investigated by means of thermogravimetric analysis (TG). Figure 1 shows the mass loss of Klason lignin (LKL) as a function of temperature.

In general, there are three main events of mass loss. The first stage occurs around $60{ }^{\circ} \mathrm{C}$ and corresponds to the removal of moisture from the material. ${ }^{11} \mathrm{~A}$ second event starts at $107{ }^{\circ} \mathrm{C}$ and ends at $259^{\circ} \mathrm{C}$ and corresponds to the degradation of smaller molecules generated in the breakdown of the macromolecule during the extraction process and also the start of lignin decomposition (24.1\%). The third event occurs at $441{ }^{\circ} \mathrm{C}$ and represents approximately $42 \%$ of mass loss, which is normally associated with the degradation products of lignin, involving the fragmentation of $\alpha$ and $\beta$-aryl-alkyl-ether bonds, release of monomers and phenol derivatives, including alcohols, acids and aldehydes, together with the formation of gaseous products. ${ }^{11,12,45,46}$ According to Chaudhary and Dhepe, ${ }^{11}$ Klason-type lignin might take longer to decompose because it has a greater number of aryl-alkyl-ether bonds. In the Klason method, drastic reaction conditions are used and changes, such as breaking bonds and condensation of smaller groups, occur in the lignin structure. ${ }^{15}$

Figure 2 shows the TG of milled wood lignin (MWL), in which an initial event is observed at $40{ }^{\circ} \mathrm{C}$, corresponding to the dehydration of the sample. There is certain thermal stability of up to approximately $250{ }^{\circ} \mathrm{C}$. After this temperature, around $318{ }^{\circ} \mathrm{C}$, it presents another loss of mass of about $60 \%$. A third stage of degradation is observed between $355{ }^{\circ} \mathrm{C}$ and $498{ }^{\circ} \mathrm{C}$, which represents around $12.6 \%$ of weight loss. The method of lignin extraction by grinding and dissolving (MWL) does not cause major changes in the structure of lignin in SB when compared with other methods, since it makes use of organic solvents at room temperature and pressure. Thus, the sample still has the characteristics of the original macromolecule. ${ }^{47}$

There are differences in the thermal degradation of the lignin samples (Figs. 1 and 2), even though they are extracted from the same sample of sugarcane bagasse. It is possible to observe that almost all the material was consumed 
and the contents of ash were too low to be quantified in both cases.

Lignin samples from non-wood materials form stable complexes with carbohydrates (cellulose and hemicelluloses), which make their purification difficult. ${ }^{48}$ The behavior of these lignin-carbohydrate complexes is also different when considering each extraction method, promoting changes (reactions, condensations, etc.) in the structure of lignin.

Figure 3 shows the DSC curves of MWL and LKL lignin samples.

The DSC curve of Klason lignin (LKL) shows a marked endothermic occurrence (probably two events). An initial event at around $60{ }^{\circ} \mathrm{C}$ is related to sample dehydration and another (overlapping) event at around $100{ }^{\circ} \mathrm{C}$ is probably related to the decomposition of smaller molecules generated in the fragmentation of the macromolecule in the lignin extraction process. Near $400{ }^{\circ} \mathrm{C}$, an exothermic event is observed.

The DSC curve of milled wood lignin (MWL) points to an endothermic event at around $70{ }^{\circ} \mathrm{C}$ related to the latent heat of water loss. A possible endothermic event at around $300{ }^{\circ} \mathrm{C}$ is observed due to the break in the connection between the components of the macromolecule. At approximately $360{ }^{\circ} \mathrm{C}$, lignin pyrolysis (degradation) is observed, with exothermic evidence.

The infrared spectra of the extracted lignin samples are shown in Figure 4. The material used in this study, sugarcane bagasse, is classified as grassy and, therefore, signals can be assigned following grass models, according to Sarkanem. ${ }^{5}$ The spectrum of MWL presents a broad band centered at $3405 \mathrm{~cm}^{-1}$, which corresponds to the hydroxy groups $(\mathrm{OH})$ of aromatic or aliphatic compounds and at $2882 \mathrm{~cm}^{-1}$, the signal is assigned to aliphatic $\mathrm{C}-\mathrm{H}$. According to Saliba and collaborators, ${ }^{49}$ the band at $1641 \mathrm{~cm}^{-1}$ can be attributed to $\mathrm{C}=\mathrm{O}$ of $\mathrm{p}$-substituted ketone, the band at $1464 \mathrm{~cm}^{-1}$ to $\mathrm{C}-\mathrm{H}$ of methyl groups and the band at $1265 \mathrm{~cm}^{-1}$ to $\mathrm{C}-\mathrm{O}$ of guaiacyl rings. Inkrod and collaborators ${ }^{50}$ assigned the band at $1728 \mathrm{~cm}^{-1}$ to $\mathrm{C}=\mathrm{O}$. The band at $1043 \mathrm{~cm}^{-1}$ is typical of hemicelluloses ${ }^{51}$ and confirms their presence in MWL. This band does not appear on the LKL spectrum.

In the LKL spectrum, the broad band centered at $3402 \mathrm{~cm}^{-1}$ corresponds to the hydroxy groups $(\mathrm{OH})$ of aromatic or aliphatic compounds and the overlapping bands at 2920-2840 $\mathrm{cm}^{-1}$ can be attributed to aliphatic C-H. Inkrod and collaborators $^{50}$ studied the isolation of lignin from different sources by acid $\left(\mathrm{H}_{2} \mathrm{SO}_{4}\right)$, including sugarcane bagasse, and assigned the band at 1715 $\mathrm{cm}^{-1}$ to unconjugated stretching of $\mathrm{C}=\mathrm{O}$. The bands at $1618 \mathrm{~cm}^{-1}$ were attributed to vibrations of the aromatic skeleton by the authors. The band at $1051 \mathrm{~cm}^{-1}$ is attributed to aromatic C-H. The bands at 1180 and $1300 \mathrm{~cm}^{-1}$ (overlapping) are assigned to $\mathrm{S}=\mathrm{O}$ groups and the band at $870 \mathrm{~cm}^{-1}$ to S-O groups. These bands do not appear on the spectrum of MWL.

It is observed that different extraction methods have a unique influence on the structure of lignin. Since it is performed under more drastic conditions, the Klason method promotes greater changes in the structure of lignin than the method by solvent extraction (MWL).

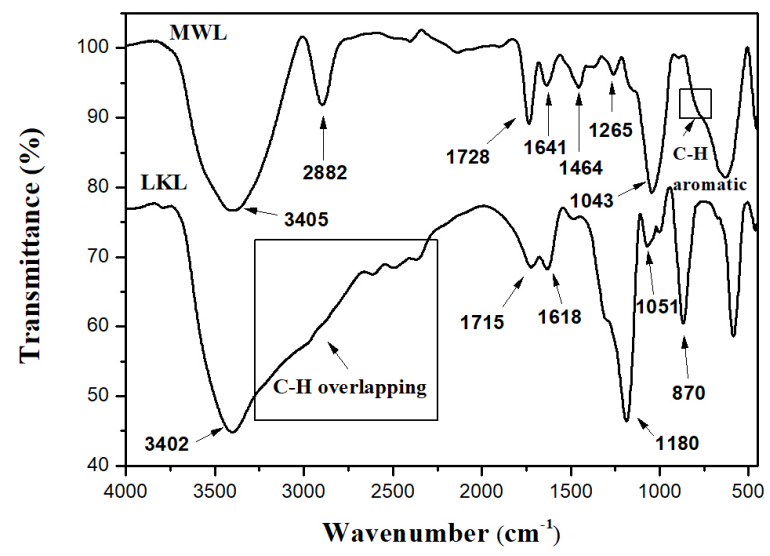

Figure 4: FTIR of milled wood lignin (MWL) and Klason lignin (LKL) 
Table 2

Elemental analysis (CHNS) of extracted lignin samples (LKL and MWL)

\begin{tabular}{lccccc}
\hline Lignin/method & $\mathrm{C}(\%)$ & $\mathrm{H}(\%)$ & $\mathrm{N}(\%)$ & $\mathrm{S}(\%)$ & $* \mathrm{O}(\%)$ \\
\hline Klason lignin (LKL) & 28.50 & 3.27 & 1.21 & 8.24 & 58.78 \\
Milled wood lignin (MWL) & 30.97 & 4.36 & 0.65 & 0.05 & 63.97 \\
\hline * Obtained by difference & & & & &
\end{tabular}

The quantification of the elemental components carbon, hydrogen, nitrogen, sulfur and oxygen (performed by difference) of the lignin samples is shown in Table 2.

The contents of $\mathrm{C}$ in the lignin samples are low. Due to the use of sulfuric acid in the extraction, LKL has a high percentage of sulfur, while MWL has a large amount of oxygen, which might be associated with the complex lignin carbohydrates. ${ }^{48}$ Even if the lignin samples were obtained from the same sample of sugarcane bagasse, it appears that the different methods showed different amounts of the analyzed elements ( $\mathrm{C}, \mathrm{H}, \mathrm{N}$ and $\mathrm{S})$.

The calorific power analyses were performed on the studied lignin samples and the values of 15.19 and $13.00 \mathrm{MJ} \mathrm{kg}^{-1}$ were found for LKL and MWL, respectively.

\section{CONCLUSION}

This study provides information on some modifications caused to sugarcane bagasse lignin promoted by different extraction methods. Sugarcane bagasse lignin has more syringyl groups than guaiacyl in its composition. The products of both extractions (LKL and MWL) are different compounds from the original lignin of the sugarcane bagasse. Thermogravimetric analysis showed that MWL loses a higher percentage of mass at a lower temperature than LKL. FTIR spectra showed the presence of sulfur-containing compounds in LKL and the presence of hemicelluloses in MWL. This study can contribute to future studies on the transformation of lignin into products with higher added value.

ACKNOWLEDGEMENTS: This study was partially financed by the "Coordination for the Improvement of Higher Education Personnel" Brazil (CAPES), FAPEMIG and CNPq - Finance Code 001. Acknowledgments are due to the Centre of Analysis and Chemical Prospecting (CAPQ-UFLA) for FTIR and TG/DSC analyses.

\section{REFERENCES}

1 J. Fiorelle, F. A. R. Lahar, M. F. Nascimento, H. S. Junior and J. A. Rossignolo, Acta Sci. Technol., 401, 33

https://doi.org/10.4025/actascitechnol.v33i4.9615 (2011),

2 S. S. Soares, J. B. G. Júnior, L. M. Mendes, R. F. Mendes, T. P. Protásio et al., Revista Ciência da Madeira, $\quad$ 64, $\quad 8 \quad$ (2017), http://dx.doi.org/10.15210/cmad.v8i2.10589

3 Brasil, Ministério da Agricultura, Cana-de-açúcar, http://www.agricultura.gov.br/vegetal/culturas/canade-acucar (acessado em 05 de fevereiro de 2018

4 L. Carvalho, R. C. O. F. Bueno, M. M. Carvalho, A. L. Favoreto and A. F. Godoy, in "Enciclopédia Biosfera", vol. 9, n. 16, p. 530-542, 2013, http://hdl.handle.net/11449/137601

5 K. V. Sarkanem and C. H. Ludwig, "Lignins: Occurrence, Formation, Structure and Reactions", New York, John Wiley and Sons, 1971, pp. 916

6 F. J. B. Gomes, A. F. G. Gouvêa, J. L. Colodette, J. L. Gomide, A. M. M. L. Carvalho et al., O Papel, 95 , 69 (2008),

http://www.revistaopapel.org.br/publicacoes.php?id=1 43

7 D. Pasquini, D. T. Balogh, P. A. Antunes, C. J. L. Constantino, A. A. S. Curvelo et al., Langmuir, 6593, 18 (2002), https://doi.org/10.1021/la025729v

8 M. J. John and S. Thomas, Carbohyd. Polym., 343, 71

(2008),

https://doi.org/10.1016/j.carbpol.2007.05.040

9 S. Al Arni, Ind. Crop. Prod., 330, 115 (2018), https://doi.org/10.1016/j.indcrop.2018.02.012

10 G. Tian, J. Xu, Y. Fu, Y. Guo, Z. Wang et al., Ind. Crop. $\quad$ Prod., 142, $131 \quad$ (2019), https://doi.org/10.1016/j.indcrop.2019.01.048

11 R. Chaudhary and P. Dhepe, Energ. Fuel, 4369, 33 (2019),

https://doi.org/10.1021/acs.energyfuels.9b00621

12 J. Bortoluz, A. Cemin, L. R. Bonetto, F. Ferrarini, V. I. Esteves et al., Cellulose, 4895, 26 (2019), https://doi.org/10.1006/anbo.2001.1482

13 M. Balakshin, E. Capanema, H. Gracz, H. M. Chang and H. Jameel, Planta, 1097, 233 (2011), https://doi.org/10.1007/s00425-011-1359-2

14 D. Tarmadi, T. Yoshimura, Y. Tobimatsu, M. Yamamura, T. Miyamoto et al., Wood Sci., 464, 63 (2017), https://doi.org/10.1007/s10086-017-1638-z

15 J. L. Gomide and B. J. Demuner, O papel, 36, 47 (1986) 
16 A. Tolbert, H. Akinosho, R. Khunsupat and A. K. Naskar, Biofuel. Bioprod. Biorefin., 836, 8 (2014), https://doi.org/10.1002/bbb.1500

17 American Society for Testing Materials, ASTM E711-87, 2004

18 W. S. Faria, T. P. Protásio, P. F. Trugilho, B. L.C. Pereira, A. C. O. Carneiro et al., Coffee Sci., 137, 11 (2016), https://doi.org/10.25186/cs.v11i1.1050

19 Deutsches Institut Für Normung, DIN EN 14774-1, 2010

20 Associação Brasileira de Normas Técnicas (ABNT), NBR 14853, 2010

21 American Society for Testing Materials, ASTM D 1762-84, 2007

22 S. Y. Lin and C. W. Dence, "Methods in Lignin Chemistry", Berlin, Springer Verlag, 1992, pp. 301320

23 Technical Association of the Pulp and Paper Industry, TAPPI T $204 \mathrm{~cm}-97,1997$

24 A. Bjorkman, Svensk Papperstidn., 477, 59 (1956)

25 Associação Brasileira Técnica de Celulose e Papel (ABTCP), Normas Técnicas (M5/68), 1974

${ }^{26}$ Associação Brasileira de Normas Técnicas (ABNT), NBR 8633, 1974

27 L. Cortez, P. Magalhães and J. Happ, Revista Brasileira de Energia, 111, 2 (1992)

28 A. A. Guilherme, P. V. F. Danta, E. S. Santos, F. A. N. Fernandes and G. R. Macedo, Braz. J. Chem. Eng., 23, 32 (2015), http://dx.doi.org/10.1590/01046632.20150321s00003146

29 A. Demirbas, Energ. Explor. Exploit., 105, 20 (2002),

https://doi.org/10.1260\%2F014459802760170420

${ }^{30}$ T. C. Ripoli, W. F. Molina Junior, J. P. Stupiello, M. C. Nogueira and J. B. Saccomano, Stab, 10, 22 (1991), http://www.stab.org.br/

31 B. M. Jenkins, L. L. Baxter, T. R. Miles Jr. and T. R. Miles, Fuel Process. Technol., 17, 54 (1998), https://doi.org/10.1016/S0378-3820(97)00059-3

${ }^{32}$ T. P. Protásio, L. Bufalino, G. H. Tonoli, A. Couto, A. P. F. Trugilho et al., Pesqui. Florest. Bras., 113, 31 (2011), https://doi.org/10.4336/2011.pfb.31.66.113

33 S. Katyal, K. Thambimuthu and M. Valix, Renew. Energ., 713, 28 (2003), https://doi.org/10.1016/S09601481(02)00112-X

34 T. V. Pereira and O. Seye, in Procs. $8^{\circ}$ Encontro de Ensino, Pesquisa e Extensão Universitária da UFGD and $5^{\circ}$ Encontro da UEMS, 20-24 october, 2014
35 C. Huang, L. Han, Z. Yang and X. Liu, J. Waste Manag., 1793, 29, (2009), https://doi.org/10.1016/j.wasman.2008.11.027

36 W. F. Quirino, "Utilização energética de resíduos vegetais”, Brasília, LPF/IBAMA, 2003, pp. 14

37 D. R. Nhuchhen and P. Abdul Salam, Fuel, 55, 99 (2012), https://doi.org/10.1016/j.fuel.2012.04.015

38 C. Yin, Fuel, 1128, 90 (2011), https://doi.org/10.1016/j.fuel.2010.11.031

39 M. Silva and A. Morais, in Procs. $39^{\circ}$ Encontro Nacional de Engenharia de Produção, Rio de Janeiro, 13-16 october, 2008

${ }^{40}$ L. L. Aló, P. A. Konishi, G. B. Belini, J. P. Silva, M. P. Martins et al., Rev. Virtual Quím., 774, 9 (2017), http://dx.doi.org/10.21577/1984-6835.20170048

41 B. O. Fernandez, B. F. Gonçalves, A. C. C. Pereira, A. L. S. Hansted, F. A. Pádua et al., Rev. Virtual Quím., 29, 9 (2017), http://dx.doi.org/10.21577/19846835.20170005

42 J. C. Río, A. G. Lino, J. L. Colodette, C. F. Lima, A, Gutiérrez et al., Biomass Bioenerg., 322, 8 (2015), https://doi.org/10.1016/j.biombioe.2015.07.006

43 V. L. Chiang, Agric. Biotechnol., 139, 17 (2005)

44 A. F. Gouvea, A. M. M. L. Carvalho, C. M. Silvia, A. C. O. Carneiro, P. F. Trugilho et al., Ciencia Florestal, $\quad \mathbf{1 0 2 9}, \quad 27 \quad$ (2017), https://doi.org/10.5902/1980509828678

45 D. Watkins, Md. Nuruddin, M. Hosur, A. TcherbiNarteh and S. Jeelani, J. Mater. Res. Technol., 26, 4 (2015), https://doi.org/10.1016/j.jmrt.2014.10.009

46 A. Tejado, C. Peña, J. Labidi, J. M. Echeverria and I. Mondragon, Bioresour. Technol., 1655, 98 (2007), https://doi.org/10.1016/j.biortech.2006.05.042

47 D. Fengel and G. Wegener, "Wood Chemistry, Ultrastructure, Reactions", New York, Walter De Gruyter, 1989 pp. 613

48 A. U. Buranov and G. Mazza, Ind. Crop. Prod, 237, 28 (2008),

https://doi.org/10.1016/j.indcrop.2008.03.008

49 E. O. S. Saliba, N. M. Rodriguez, S. A. L. Moraes and D. Pilo-Veloso, Cienc. Rural, 917, 31 (2001), http://dx.doi.org/10.1590/S0103-84782001000500031

50 C. Inkrod, M. Raita, V. Champreda and N. Laosiripojana, BioEnerg. Res., 277, 11 (2018), https://doi.org/10.1007/s12155-018-9895-2

51 A. U. Buranov, K. A. Ross and G. Mazza, Bioresour. Technol., 7446, $101 \quad$ (2010), https://doi.org/10.1016/j.biortech.2010.04.086 